\title{
A Rare Case of Oxidised Cellulose Causing an Reaction Mimicking Post Thyroidectomy Abscess Formation - A Case Report \& Review of Literature
}

\author{
Case Report
}

Rubecka $\mathrm{S}^{*}$, Mihaimeed $\mathrm{F}^{*}$

Newham University Hospital, Barts Health NHS Trust, London, UK.

Keywords: Thyroidectomy; Delayed Type Hypersensitivity; Regenerated Oxidized Cellulose.

\section{Introduction}

Oxidized cellulose is a form of absorbable oxidised cellulose polymer made of polyanhydroglucuronic acid, which is used as a haemostatic agent for years [1-3]. In addition, it has properties of adhesion prevention and a wide range of bactericidal actions including Methicillin Resistant Staphylococcus Aureus, Staphylococcus epidermidis, Pseudomonas Aeruginosa and Streptococcus Pneumoniae [3, 4]. Though, it is known to mimic abscesses in long term follow up of patients with ultrasound neck in case series, it is rarley reported to cause any hypersensitivity reaction in neck in the literature $[4,7,12,14]$.

\section{Case Report}

We present a 48-year-old lady who had a toxic goiter intolerant to medical management. She has a background of poorly controlled type II DM, penicillin allergy and multiple intolerances such as plaster, ibuprofen, codeine and carbimazole leading to liver failure. She underwent total thyroidectomy following 10 days of $1 \%$ Lugol's iodine.

Her preoperative thyroid function tests were high, TSH being $<0.01 \mathrm{mU} / \mathrm{L}$ and free T4 being $29.9 \mathrm{pmol} / \mathrm{L}$. She was on propranolol $20 \mathrm{mg}$ twice daily for symptom control and calcium supplementation for low calcium. Preop HbA1C was high, being 8.4, but preoperatively her blood sugar levels were within the normal range and she was on sliding scale of insulin.

We performed a total thyroidectomy via a $4 \mathrm{~cm}$ incision. Her deep cervical fascia was approximated with 30 vicryl (polyglactin 910) and skin with clips and steristrips. We placed 2 pieces of Equitamp (R) brand regenerated oxidized cellulose, with dimensions of $4 \mathrm{~cm} \mathrm{X} 1 \mathrm{~cm}$ bilaterally in the thyroid bed, near recurrent laryngeal nerves as a haemostatic agent, as the senior author has used oxidised cellulose from another manufacturer for thyroid surgeries in his past 19 years without any complication. Her surgery was uneventful.

She was monitored for first postoperative 24 hours in the recovery expecting a thyroid storm. She was clinically and biochemically well on postoperative day 1 (Figure 1). Her wound was nice and tidy and we removed her clips and replaced with steristrips. Her drains were minimal and were removed.

During next 24-48 hours she developed some erythema extending from neck to upper chest and gradual painless neck swelling initially, which became painful with progression of the swelling. To complicate the matters, she also developed a chest infection. Her skin erythema was initially managed as cellulitis and improved rapidly being confined to her lower neck by day 5 (Figure 2). Although the inflammatory markers were high initially white count being $15.1 \times 10^{9} / \mathrm{L}$ with a neutrophilia of $10.7 \times 10^{\circ} / \mathrm{L}$ and a

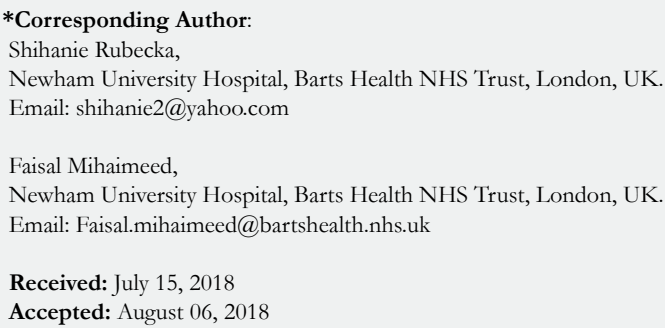

Citation: Rubecka S, Mihaimeed F. A Rare Case of Oxidised Cellulose Causing an Reaction Mimicking Post Thyroidectomy Abscess Formation - A Case Report \& Review of Literature. Int J Surg Res. 2018;5(6):119-122. doi: http://dx.doi.org/10.19070/2379-156X-1800026

Copyright: Rubecka S, Mihaimeed $\mathbf{F}^{\circ}$ 2018. This is an open-access article distributed under the terms of the Creative Commons Attribution License, which permits unrestricted use, distribution and reproduction in any medium, provided the original author and source are credited. 
CRP of $269 \mathrm{mg} / \mathrm{L}$, it settled gradually with treatment of the chest infection, white count coming down to $9.3 \times 10^{\circ} / \mathrm{L}$ with a CRP of $4 \mathrm{mg} / \mathrm{L}$.

During next week, she had a couple of ultrasound scans which were not helpful. She had guided aspirations from neck collection, which yielded pus like material, but culture yielded only skin commensals or no growth continuously. She had her chest infection for 3-4 days and settled down from her systemic symptoms completely and inflammatory markers came to baseline gradually.

Despite systemic and biochemical improvement, she continued herself like this and started leaking from the wound on postoperative day 10 (Figure 3). Since a hypersensitivity reaction was not expected she was managed continuously with conservative measures with regular wound dressings and antibiotics as per microbiologists advise. After couple of days her wound started gaping and whitish colour material was coming from the wound. She was managed at the bed site conservatively with continuous wound irrigations and cleaning. Due to slow course of progression and continuous discharge she had a complete wound opening, cleaning with complete removal of the oxidized cellulose, after which her discharge settled completely. She had secondary closure of the wound under local anaesthesia and later stayed in the hospital for refractory hypocalcaemia under endocrine colleagues (Figure $4)$.

On retrospective review of the literature her pictures looked quite similar to pictures published by Royds et al., in 2012 for the first case of oxidized cellulose causing a reaction mimicking a thyroid abscess. As in a typical delayed hypersensitivity reaction, her erythema started 48-72 hours postoperatively after the placing the oxidized cellulose in the thyroid bed. After her initial chest infection settled within first week, her systemic symptoms and inflammatory markers settled, though her swelling continued to grow and started leaking material mimicking pus. The problem persisted until the complete removal of the oxidized cellulose up to 16 to 18 days. Once it was removed completely, the discharge completely stopped and she made a progress in her recovery and the wound was closed by secondary closure.

After the initial case report, no other similar cases were reported until we encountered this interesting lady.

Figure 1. Post Operative Day 1.

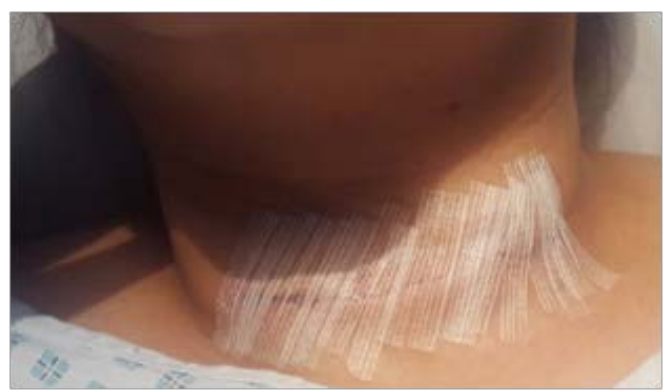

Figure 2. Postoperative Day 4.

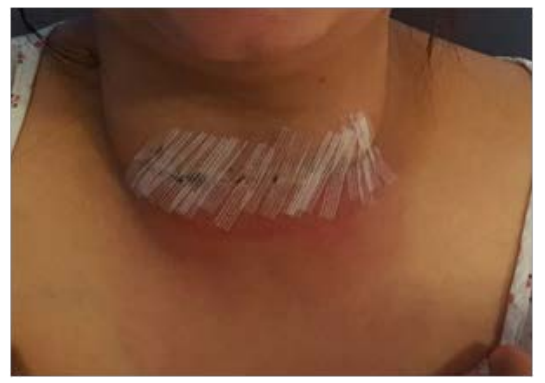

Figure 3. Postoperative Day 10.

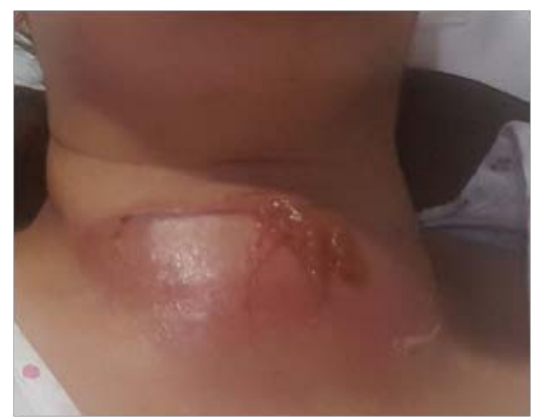

Figure 4. Completely Healed Wound.

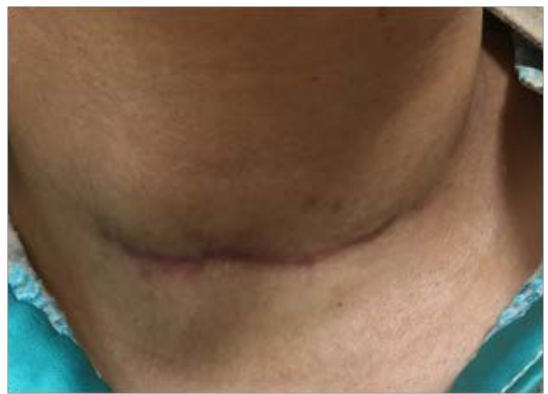

Figure 5. Brand of Oxidized Cellulose we Used.

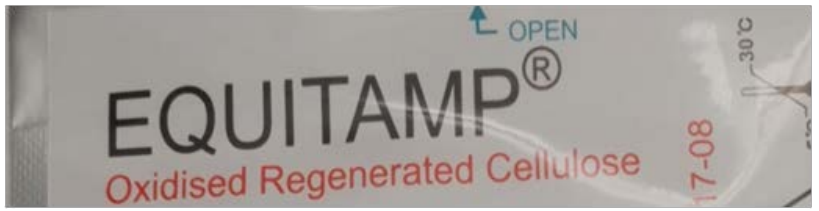

Figure 6. This is an Ultrasonic Picture of One of Our Patients who Mimicked a Post Thyroidectomy Abscess Formation after Placing the Surgicel in the Thyroid Bed.

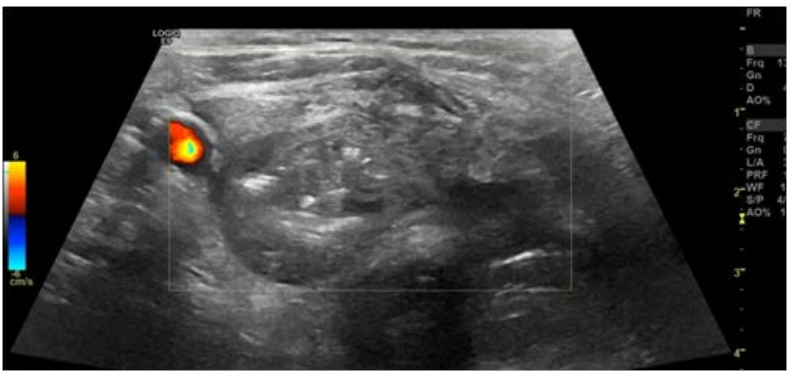




\section{Discussion and Review of Literature}

The senior surgeon's practice over the 19 years included insertion of small peice of SURGICEL ${ }^{(\mathrm{R})}$ oxidized cellulose, with very rare encounter of post operative seroma formation. However; the hospital procurement contracted a new product of oxidized cellulose - Equitamp ${ }^{(R)}$ (Figure 5). After use of this new product of oxidized cellulose in thyroidectomies, the senior author came across a series of 3 seromas in thyroidectomy patients. They were reported by the radiology colleagues as abscess formation in the thyroid bed (Figure 6). However, those patients were not showing symptoms or signs of abscesses clinically and biochemically and remained stable, apart from swelling and resolved on its own, during due course.

Oxidized cellulose is a topical haemostat launched in the clinical market in 1960s [5]. It is a unique plant-based product that was made by regenerating pure plant-derived cellulose into a knitted fabric which is then oxidized $[1,3,5]$. The fabric acts as a scaffold for clot formation by promoting platelet adhesion and aggregation. Its biodegradation starts within 24-48 hours and depending on the amount used and type of tissue bed applied, it should be completely absorbed within $4-8$ weeks [1-5]. Within the first week, multinucleated giant cells appear along with inflammatory granulation tissue $[1,2,5]$.

Many complications noted with oxidized cellulose include pseudo abscess formation, granuloma formation, prolonged drainage, pseudo cancers, paraplegia, obstructive hydrocephalus and obstructive uropathy. The complications noted mainly with neurosurgical, abdominal including renal,hepato biliary, gynaecological and cardiothoracic surgeries [4, 6-18]. The majority of these cases presented with pain or on routine follow up imaging between 6 to 52 weeks $[4,6,18]$. In most cases, the presentation was due to type IV delayed type hypersensitivity reaction [4, 6-8].

Most of the cases with related to abdomen was managed conservatively while in neurosurgery the offending oxidized cellulose, causing obstruction had to be removed due to oedema of surrounding tissue causing pressure $[6,9,12,16,18]$.

Royds et al., in 2012 described a 56-year-old lady who had uneventful recovery after thyroidectomy presenting 30 days postoperatively with multiple sinuses in the neck with pieces of oxidized cellulose protruding from the wounds. As in our case, removal of oxidized cellulose completely and promptly resolved the problem. It was reported as the first case to mimic a neck abscess due to a reaction following use of oxidized cellulose [4].

Gupta et al., in 2010 reported a case of prolonged drainage following left partial nephrectomy in a 1.2-year-old child conversely proportionating with ultrasonic thickness of the oxidized cellulose. When the oxidized cellulose thickness reduced, the surgical drainage output was reduced [6].

Zhang et al., in 2015 reported a case of a girl presenting 1 week after right ovarian cystectomy with acute abdominal pain with imaging mimicking abscess formation. She was managed conservatively and the pain seemed to disappear after radiological evidence of absorption of oxidized cellulose [9].
Menowsky et al., in 2011, Dogan in 2005 and Brodbelt in 2002 have reported many cases where oxidized cellulose induced swelling contributed in neurological deficits in patients and outcome was to minimize intraoperative use of oxidized cellulose and once the haemostasis is achieved to remove oxidized cellulose before final closure [16].

Although there were no mortalities due to adverse effects from oxidized cellulose there were morbidities encouraging minimum use of oxidized cellulose. Sufficient importance is not given as many cases were attributed to excessive usage of oxidized cellulose $[6,10,14,16,18]$.

In a series of approximately 800 thyroidectomies over 19 years performed by the senior author, this is the first case of reaction caused by oxidised cellulose.

Some surgeons believe oxidized cellulose reduces the surgical time especially in the presence of a small ooze. In addition, since we attempt to avoid energy devices, unnecessary handling, accidental ligatures near recurrent laryngeal nerve, oxidized cellulose is a perfect haemostat during thyroid surgery.

\section{Conclusion}

Products of oxidized cellulose are still used extensively as one of the most valuable haemostatic materials for their intended use. Their benefits outweighs the risks as discussed. This case report intended to share experience and raise awareness about a rare surgical complication of the oxidized cellulose haemostaic product, and to raise awareness about the confusing radiological and sonographic features that mimic abscess formation.

\section{References}

[1]. Armstrong JK, Han B, Kuwahara K, Yang Z, Magyar CE, Dry SM, et al. The effect of three hemostatic agents on early bone healing in an animal model. BMC Surg. 2010 Dec 17;10:37. doi: 10.1186/1471-2482-10-37. PubMed PMID: 21167039.

[2]. Keshavarzi S, MacDougall M, Lulic D, Kasasbeh A, Levy M. Clinical experience with the surgicel family of absorbable hemostats (oxidized regenerated cellulose) in neurosurgical applications: a review. Wounds. 2013 Jun;25(6):160-7. PubMed PMID: 25866982.

[3]. Peralta E. Overview of topical hemostatic agents and tissue adhesives.

[4]. Royds J, Kieran S, Timon C. Oxidized cellulose (Surgicel) based reaction post thyroidectomy mimicking an abscess: A case report. Int J Surg Case Rep. 2012;3(7):338-9. doi: 10.1016/j.ijscr.2012.03.034. PubMed PMID: 22572542.

[5]. Sundaram CP, Keenan AC. Evolution of hemostatic agents in surgical practice. Indian J Urol. 2010 Jul;26(3):374-8. doi: 10.4103/0970-1591.70574. PubMed PMID: 21116358.

[6]. Gupta V, Al Said A, Kumar S, Khan AA. Surgicel as an unusual cause of prolonged drainage. J Surg Tech Case Rep. 2010 Jul;2(2):92. doi: 10.4103/2006-8808.73626. PubMed PMID: 22091346.

[7]. Salmo E, Bisset R, Aldean I. Oxidized cellulose mimicking a recurrent colorectal cancer: report of a case and review of the literature. Colorectal Dis. 2010 Apr;12(4):381-2. doi: 10.1111/j.1463-1318.2009.01808.x. PubMed PMID: 19220373.

[8]. Buckley SC, Broome JC. A foreign body reaction to Surgicel (R) mimicking an abscess or tumour recurrence. Br J Neurosurg. 1995;9(4):561-3. PubMed PMID: 7576287.

[9]. Zhang F, Bonidie MJ, Ventrelli SM, Furlan A. Intraovarian oxidized cellulose (Surgicel) mimicking acute ovarian pathology after recent pelvic surgery. Radiol Case Rep. 2015 Sep 26;10(4):39-41. doi: 10.1016/j.radcr.2015.08.002. PubMed PMID: 26649116.

[10]. Dokumcu Z, Polatdemir K, Ozcan C, Erdener A. Postoperative recurrent tracheoesophageal fistula: An unusual complication of oxidized regenerated cellulose (Surgicel ${ }^{\circ}$ ). Int J Pediatr Otorhinolaryngol. 2014 Apr;78(4):701-3. 
doi: 10.1016/j.ijporl.2014.01.034. PubMed PMID: 24576454.

[11]. Agarwal MM, Mandal AK, Agarwal S, Lal A, Prakash M, Mavuduru R, et al. Surgicel granuloma: unusual cause of "recurrent" mass lesion after laparoscopic nephron-sparing surgery for renal cell carcinoma. Urology. 2010 Aug;76(2):334-5. doi: 10.1016/j.urology.2009.06.070. PubMed PMID: 20494418.

[12]. Partheni M, Kalogheropoulou C, Karageorgos N, Panagiotopoulos V, Voulgaris S, Tzortzidis F. Radiculopathy after lumbar discectomy due to intraspinal retained Surgicel: clinical and magnetic resonance imaging evaluation. Spine J. 2006 Jul-Aug;6(4):455-8. PubMed PMID: 16825055.

[13]. Melamed JW, Paulson EK, Kliewer MA. Sonographic appearance of oxidized cellulose (Surgicel): pitfall in the diagnosis of postoperative abscess. J Ultrasound Med. 1995 Jan;14(1):27-30. PubMed PMID: 7707473.

[14]. Abs R. Cutaneous necrosis in a clinical case of one face lift after the use of surgicel. Ann Chir Plast Esthet. 2004 Feb;49(1):43-6. PubMed PMID: 15013534 .
[15]. Oto A, Remer EM, O'Malley CM, Tkach JA, Gill IS. MR characteristics of oxidized cellulose (Surgicel). AJR Am J Roentgenol. 1999 Jun;172(6):14814. PubMed PMID: 10350276.

[16]. Menovsky T, Plazier M, Rasschaert R, Maas AI, Parizel PM, Verbeke S. Massive swelling of Surgicel ${ }^{\ominus}$ Fibrillar ${ }^{\text {th }}$ hemostat after spinal surgery. Case report and a review of the literature. Minim Invasive Neurosurg. 2011 Oct;54(56):257-9. doi: 10.1055/s-0031-1284394. PubMed PMID: 22278791.

[17]. Dogan S, Kocaeli H, Doygun M. Oxidised regenerated cellulose as a cause of paraplegia after thoracotomy: case report and review of the literature. Spinal Cord. 2005 Jul;43(7):445-7. PubMed PMID: 15897919.

[18]. Brodbelt AR, Miles JB, Foy PM, Broome JC. Intraspinal oxidised cellulose (Surgicel) causing delayed paraplegia after thoracotomy--a report of three cases. Ann R Coll Surg Engl. 2002 Mar;84(2):97-9. PubMed PMID: 11995773 